ВІСНИК

ОДЕСЬКОГО НАЦІОНАЛЬНОГО

МОРСЬКОГО УНІВЕРСИТЕТУ

№ 3 (63), 2020
HERALD

OF THE ODESSA NATIONAL

MARITIME UNIVERSITY № 3 (63), 2020

УДК 37.018.43

DOI 10.47049/2226-1893-2020-3-165-186

\title{
ИССЛЕДОВАНИЯ ПРОБЛЕМЫ ФОРМИРОВАНИЯ СОВРЕМЕННЫХ ПОДХОДОВ К МЕТОДОЛОГИИ ДИСТАНЦИОННОГО ОБУЧЕНИЯ
}

\section{Л.В. Кошарская}

к.т.н., доцент кафедры «Техническое обслуживание и ремонт судов»

Одесский национальный морской университет, Украина, Одесса

\section{В.П. Бреднёва}

к.т.н., профессор кафедры «Начертательная геометрия и инженерная графика»

Одесская государственная академия строительства и архитектуры

\section{А.В. Левицкий}

руководитель отдела Высшей школы Коммерции НЕС

Компания Бомбардье Транспорт, Вена, Австрия

Аннотация. В статье рассматриваются основные проблемы методологии дистанционного обучения $u$ формирование некоторых современных подходов к его усовершенствованию. В условиях широкой информатизации одним из наиболее важных факторов обучения является осмысленность учащимися учебного материала, и роль преподавателя заключается, прежде всего, с одной стороны, в максимальном расширении смыслового поля изучаемого материала, а, с другой стороны, $в$ его конкретике и детализации. Взаимодействие реальных субъектов образования в виртуальной среде осуществляется при помощи спещиальных средств коммуникации, к которым предъявляются особые требования - организачионные, технические, психолого-педагогические и т.n.

Ключевые слова: дистанционное обучение, методологические и психолого-педагогические принципы, современные подходы к технологии и организаџии дистаниионного образования.

УДК 37.018.43

DOI 10.47049/2226-1893-2020-3-165-186

\section{ДОСЛІДЖЕННЯ ПРОБЛЕМИ ФОРМУВАННЯ СУЧАСНИХ ПІДХОДІВ ДО МЕТОДОЛОГІЇ ДИСТАНЦІЙНОГО НАВЧАННЯ}

\section{Л.В. Кошарська}

к.т.н., доцент кафедри «Технічне обслуговування і ремонт суден»

Одеський національний морський університет, Украина, Одесса

В.П. Бредньова

к.т.н.,професор кафедри «Нарисна геометрія та інженерна графіка»

Одеськая державна академія будівництва та архітектури

А.В. Левицький

керівник відділу Вищої школи Комерції НЕС

Компанія Бомбардье Транспорт, Відень, Австрія

() Кошарская Л.В., Бреднёва В.П., Levitsckiy А., 2020 
ВІСНИК

ОДЕСЬКОГО НАЦІОНАЛЬНОГО

МОРСЬКОГО УНІВЕРСИТЕТУ

№ 3 (63), 2020
HERALD

OF THE ODESSA NATIONAL

MARITIME UNIVERSITY

№ 3 (63), 2020

Анотація. У статті розглядаються основні проблеми методологї дистанційного навчання $i$ формування деяких сучасних підходів до його удосконалення. В умовах широкої інформатизачії одним $з$ найважливі-ших факторів навчання $є$ осмисленість учнями навчального матеріалу, i роль викладача полягає, перш за все, з одного боку, в максимальному розширенні смислового поля досліджуваного матеріалу, a, з іншого боку, в його конкретиці та деталізащії. Взаємодія реальних суб'єктів освіти в віртуальному середовищі здійснюється за допомогою спеціальних засобів комунікації, до яких пред'являються особливі вимоги - організаційні, технічні, психолого-педагогічні.

Ключові слова: дистаниійне навчання, методологічні та психолого-педагогічні принципи, сучасні підходи до технології та организачії дистанційної освіти.

UDC 37.018.43

DOI 10.47049/2226-1893-2020-3-165-186

\section{RESEARCHES OF PROBLEM OF FORMING OF MODERN GOING NEAR METHODOLOGY OF THE CONTROLLED FROM DISTANCE EDUCATING}

\section{Kosharska}

candidate of engineering sciences

Professor of department of «Technical Service and Repair of Ships»

Odessa National Maritime University, Ukraine, Odessa

\section{Brednyova}

candidate of engineering sciences

Professor of department of «Descriptive Geometry and Engineer Graphics»

Odessa State Academy of Civil Engineering and Architecture

\section{A. Levytsckiy}

MBA HEC School of Management

Head of Procurement Business Partners

Small Markets Bombardier Transportation, Vienna, Austria

Abstract. In the article the basic problems of methodology of the controlled from distance educating and forming of some modern going are examined near his improvement. In the conditions of wide informatization one of the most essential factors of educating is intelligentness by students educational material, and the role of teacher consists, foremost, from one side, in maximal expansion of the semantic field of the studied material, and, on the other hand, in his reality and working out in detail. Cooperation of the real subjects of education in a virtual environment comes true through the special facilities communications to that the special requirements are produced organizational are technical, psychological and pedagogical etc.

Keywords: controlled from distance educating, methodological, psychological and pedagogical principles, modern going near technology and organization of the controlled from distance education. 
Введение. Дистанционное образование (ДО) - это общий термин, который включает в себя ряд стратегий обучения, используемых университетами, отделами дистанционного обучения университетов, высшими учебными заведениями, колледжами, школами и различными другими учебными подразделениями дистанционного обучения. Таким образом, этот термин используется для обозначения образования тех, кто по тем или иным причинам предпочитает не посещать обычные школы, колледжи или университеты, а учиться дома. Одним из наиболее полных определений, на наш взгляд, можно считать следующее: дистанционное образование характеризуется разделением ученика и наставника в противоположность личному обучению, влиянию образовательной организации, которая отличает дистанционное образование от частного обучения, использование технических средств информачии, например, печать, аудио или веб-сайты, чтобы объединить преподавателя и ученика, обеспечить двустороннюю связь, чтобы учащийся мог вести диалог с преподавателем, возможность встреч для иелей самонаправленного характера общения и взаимодействия учащегося и преподавателя

Постановка проблемы. Современное общество разрушает исторически сложившиеся стереотипы учебного процесса. Дистанционное обучение на сегодня одна из базовых составляющих учебного процесса. Стоимость образования постоянно растёт, а количество людей, имеющих возможность получить образование, сокращается. Концептуальная основа дистанционного образования характеризуется тем, что оно сосредоточено на открытом доступе к образованию и обучению, освобождая учащихся от ограничений времени и места и предлагая гибкие возможности обучения для отдельных лиц и групп учащихся. Между преподавателем и учеником существует двусторонняя связь - это можно назвать косвенным взаимодействием, которое происходит в основном через почту и может быть дополнено электронными средствами массовой информации. Еще одной характерной особенностью дистанционного обучения является либо контактная сессия, либо консультации, направленные на решение вопросов учащихся, Дистанционный режим образования играет важную роль в удовлетворении потребностей таких лиц, которые пользуются большим спросом на образование, но не могут завершить свое образование из формальной или регулярной системы образования.

Задачами нашей работы является изучение проблем, связанных с дистанционным обучением, исследование современных подходов к методологии дистанционного обучения и разработка некоторых рекомендаций решения проблем, с которыми сталкиваются дистанционные ученики.

Основной материал. Процесс информатизации образования, поддерживая интеграционные тенденции познания закономерностей развития предметных областей и окружающей среды, актуализирует разработку подходов к использованию потенциала информационных технологий обучения для развития личности обучающихся, повышения уровня креа- 
ВІСНИК

ОДЕСЬКОГО НАЦІОНАЛЬНОГО

МОРСЬКОГО УНІВЕРСИТЕТУ № 3 (63), 2020
HERALD

OF THE ODESSA NATIONAL

MARITIME UNIVERSITY № 3 (63), 2020

тивности их мышления, формирования умений разрабатывать стратегию поиска решения как учебных, так и практических задач, прогнозировать результаты реализации принятых решений на основе моделирования изучаемых объектов, явлений, процессов, взаимосвязей между ними. В процессе зарождения и развития информационного общества огромное значение имеют проблемы, связанные с организацией образовательного процесса.

Роль среды в образовании осознаётся и осмысливается, начиная с древнегреческих времен. Платоновская Академия, Аристотелевский Ликей были образовательной средой античности. Монастырь был такой средой для средневекового образования. Мастерская художника и учёногоэкспериментатора воспитывали титанов Возрождения. Университет и школа стали символами образовательной среды Нового времени вплоть до наших дней. Чертой настоящего времени является виртуальная образовательная среда.

Перспективная система образования должна быть способна не только вооружать знаниями обучающегося, но и вследствие постоянного и быстрого обновления знаний в нашу эпоху формировать потребность в непрерывном самостоятельном овладении знаниями, умениями и навыками самообразования, а также самостоятельной и творческой деятельности в течение всей активной жизни человека. В последнее время в образовательной сфере предлагаются различные технологии и формы обучения, позволяющие повысить уровень и эффективность образования. Это обусловливается тем, что учебный процесс подчинен не столько задаче информационного насыщения, сколько формированию продуктивного мышления, развитию интеллектуального потенциала личности, становлению способов логического анализа и всесторонней обработки потребляемой информации, творческому конструированию.

Роль ДО в активизации самостоятельной работы студентов технического вуза находится на низком уровне. Осознание студентами значимости личной самостоятельности в своем профессиональном становлении происходит лишь на завершающем этапе обучения. Это, безусловно, сказывается на качестве формирования профессиональных компетентностей будущих специалистов, их способности адаптироваться в изменяющихся профессиональных и общественных условиях. В то же время необходимо особо отметить, что развитию самостоятельности в процессе обучения в высшей школе уделяется недостаточно внимания. Особенно актуальна эта проблема для технических вузов. Преподаватели высших учебных заведений негуманитарного профиля в своем большинстве не имеют психолого-педагогических компетенций и нуждаются в соответствующей поддержке для использования адекватных задачам своей дисциплины способов развития самостоятельности студентов. Существенную помощь могут оказать специальные курсы повыщения квалификащии, где психологопедагогический аспект в приоритете. Кроме того, необходимо отметить 
ВІСНИК

ОДЕСЬКОГО НАЦІОНАЛЬНОГО

МОРСЬКОГО УНІВЕРСИТЕТУ № 3 (63), 2020
HERALD

OF THE ODESSA NATIONAL

MARITIME UNIVERSITY № 3 (63), 2020

недостаток учебной литературы, направленной на развитие умения студентов самостоятельно получать и осваивать знания по предмету, оценивать их усвоение, что, безусловно, является мотивацией к самообразованию и к саморазвитию студентов. Таким образом, необходимость и практическая значимость дистанционных форм образования и для преподавателей, и для обучающихся определяется потребностью в развитии самостоятельности студентов и недостатком психолого-педагогического инструментария для решения данной задачи в условиях негуманитарного профиля.

Сегодняшний уровень развития информационных и коммуникационных технологий закладывает реальный фундамент для создания глобальной системы дистанционного образования - одной из перспективных и эффективных систем подготовки специалистов. Основу образовательного процесса при дистанционном обучении составляет целенаправленная и контролируемая интенсивная самостоятельная работа школьника или студента, который может учиться в удобном для себя месте, по индивидуальному расписанию, имея при себе комплект специальных средств обучения. Ключевым понятием дистанционной формы обучения является «интерактивность», т.е. систематическое взаимодействие учителя (преподавателя) и учащегося и учащихся между собой $[8 ; 13]$.

В настоящее время основой педагогического процесса в высшей школе является формирование потребности в самообразовании посредством обучения методологии самостоятельной работы в информационнообразовательной среде и при увеличении ее доли в образовательном процессе. Система дистанционного обучения рассматривает студента как субъекта обучения, а образовательный процесс направлен не столько на трансляцию знаний, сколько на развитие познавательных способностей. При этом функции педагога варьируются от информационно-контролирующих до консультационно-координирующих. Анализ существующих форм обучения подводит нас к выводу о том, что форма обучения представляет собой способ организации образовательного процесса, отличающийся двумя основными признаками:

1 - соотношение объемов непосредственного и опосредованного педагогического общения со студентом (очная, заочная формы обучения);

2 - соотношение между объемом обязательных коллективных занятий и самостоятельной работы студентов.

В связи с этим огромную роль играет организационно-методическая деятельность преподавателя по управлению учебным процессом с использованием информационных и коммуникационных технологий и деятельность по обеспечению процесса обучения учебно-методическими материалами, обеспечивающих самостоятельную учебную деятельность студентов. 
ВІСНИК

ОДЕСЬКОГО НАЦІОНАЛЬНОГО

МОРСЬКОГО УНІВЕРСИТЕТУ № 3 (63), 2020
HERALD

OF THE ODESSA NATIONAL

MARITIME UNIVERSITY № 3 (63), 2020

Дистанционное обучение по своей сути может быть подразделено на несколько видов. Каждый вид обусловлен способом передачи и получения инструкций и материалов по обучению от преподавателя к студенту. В свою очередь, в этом процессе немалую роль играют те средства и носители информации, которые используются. Важным признаком классификации дистанционного обучения является совокупность используемых в учебном процессе педагогических методов и приемов. Выбрав в качестве критерия способ коммуникации преподавателей и обучаемых, эти методы (приемы), объединенные в четыре группы, можно классифицировать следующим образом:

- методы обучения посредством взаимодействия обучаемого с образовательными ресурсами при минимальном участии преподавателя и других обучаемых (самообучение). Для осуществления этих методов создаются различные образовательные ресурсы: печатные, аудио- и видеоматериалы, а также учебные пособия, доставляемые по телекоммуникационным сетям (интерактивные базы данных, электронные издания и компьютерные обучающие системы).

- методы индивидуализированного преподавания и обучения, для которых характерны взаимоотношения одного студента с одним преподавателем или одного студента с другим студентом (обучение «один к одному»). Эти методы могут реализоваться в дистанционном обучении в основном посредством таких технологий, как телефон, голосовая почта, факс, электронная почта.

- методы, в основе которых лежит изложение учебного материала преподавателем, при этом обучаемые не играют активной роли в коммуникации (обучение «один ко многим»). Эти методы, свойственные традиционной образовательной системе, получают новое развитие на базе современных информационных технологий. Так, лекции, записанные на аудио- или видеокассеты, читаемые по радио или телевидению, дополняются в современном дистанционном обучении так называемыми электронными лекциями, т. е. лекционным материалом, распространяемым по компьютерным сетям с помощью систем досок объявлений. Электронная лекция может представлять собой подборку статей или выдержек из них, а также учебных материалов, которые готовят обучаемых к будущим дискуссиям. На базе технологии электронной доски объявлений развивается также метод проведения учебных электронных симпозиумов, представляющих собой серию выступлений нескольких авторитетных ученых.

- методы, для которых характерно активное взаимодействие между всеми участниками учебного процесса (обучение «многие ко многим»). Значение этих методов и интенсивность их использования существенно возрастает с развитием обучающих телекоммуникационных технологий. 
ВІСНИК

ОДЕСЬКОГО НАЦІОНАЛЬНОГО

МОРСЬКОГО УНІВЕРСИТЕТУ № 3 (63), 2020
HERALD

OF THE ODESSA NATIONAL

MARITIME UNIVERSITY № 3 (63), 2020

Именно эти методы, которые ориентированы на групповую работу студентов, представляют наибольший интерес для дистанционного обучения. Обучение в сотрудничестве создает активный познавательный процесс, обеспечивая работу с различными источниками информации. Эти методы предусматривают широкое использование исследовательских и проблемных способов обучения, применение полученных знаний в совместной или индивидуальной деятельности, развитие не только самостоятельного критического мышления, но и культуры общения, умения выполнять различные социальные роли в совместной деятельности. Такие методы также наиболее эффективно решают проблемы личностно-ориентированного обучения. Студенты получают реальную возможность в соответствии с индивидуальными задатками, способностями достигать определенных результатов в различных областях знаний, осмысливать получаемые знания, в результате чего им удается сформировать собственную аргументированную точку зрения на многие жизненные проблемы [4].

При обучении в сотрудничестве решаются следующие задачи:

- студент гораздо лучше учится, если он умеет устанавливать социальные контакты с другими членами коллектива; от умения общаться с другими членами коллектива зависит и умение студентов четко излагать свои мысли, грамотно и логически писать;

- в процессе социальных контактов между студентами создается учебное сообщество людей, владеющих определенными знаниями и готовых получать новые знания в процессе общения друг с другом, совместной познавательной деятельности.

Роль преподавателя при таком обучении сводится к тому, что он задает тему для студентов (ставит учебную задачу), а далее он должен создать и поддерживать такую благоприятную среду общения и психологический климат, при которых обучаемые могли бы работать в сотрудничестве. При этом в отличие от других методов обучения преподаватель сам является полноправным участником процесса обучения, что, разумеется, не снимает с него ответственности за координацию, управление ходом дискуссий, а также за подготовку материалов, разработку плана работы, обсуждаемых вопросов и тем.

Обучение в сотрудничестве может иметь различные формы.

Метод проектов предполагает комплексный процесс обучения, позволяющий обучаемому проявить самостоятельность в планировании, организации и контроле своей учебно-познавательной деятельности, результатом которой является создание какого-либо продукта или явления. В основе метода проектов лежит развитие познавательных, творческих интересов обучаемых, умений самостоятельно формировать свои знания и ориентироваться в информационном пространстве, развитие критического мышления. 
ВІСНИК

ОДЕСЬКОГО НАЦІОНАЛЬНОГО

МОРСЬКОГО УНІВЕРСИТЕТУ № 3 (63), 2020
HERALD

OF THE ODESSA NATIONAL

MARITIME UNIVERSITY № 3 (63), 2020

Этот метод обучения всегда ориентирован на самостоятельную деятельность учащихся (индивидуальную, парную, групповую), которую обучаемые выполняют в течение определенного отрезка времени.

Методы проблемного обучения основаны на рассмотрении сложных познавательных задач, решение которых представляет существенный практический или теоретический интерес. В процессе проблемного обучения внимание студентов фокусируется на важных проблемах, они стимулируют познавательную активность, способствуют развитию умений и навыков по решению проблем. Образовательный процесс строится вокруг обучаемого, вся работа организуется в малых группах. Роль преподавателя сводится к наблюдению и поддержке, но не более.

Для исследовательского метода обучения характерно наличие четко поставленных актуальных и значимых для участников целей, продуманной и обоснованной структуры, широкого использования арсенала методов исследования, использования научных методов обработки и оформления результатов. При этом принцип доступности и содержания методов исследования становится ведущим.

Игровые методы в условиях ДО получают новое рождение. Они способны решить много проблем, вызванных спецификой образовательной среды виртуального общения. При этом игровой средой становится Интернет, что диктует свои законы дидактической реализации этого метода обучения. С педагогической точки зрения можно выделить следующие виды игр: обучающие, тренировочные, контролирующие, познавательные, воспитательные, развивающие, репродуктивные, творческие, коммуникативные, диагностические и др. По характеру игровой методики выделяются предметные, сюжетные, ролевые, деловые, имитационные и другие игры.

Для того, чтобы групповая совместная работа студентов была успешной, обучаемые осваивают ряд алгоритмов, приемов и методов совместного принятия решений, выработки общей стратегии действий и решения возникающих проблем, поиска их решений, которые успешно используют в дальнейшем в ходе сетевых дискуссий, проектов и т. д. При этом иногда может возникнуть ситуация, когда требуется принять коллективное решение или выработать новую идею в очень жесткие сроки. В этом случае хорошо зарекомендовал себя такой прием, как «мозговая атака».

Средствами дистанционного обучения могут быть:

- учебные книги (твердые копии на бумажных носителях и электронные варианты учебников, учебно-методических пособий, справочников и т. д.);

- сетевые учебно-методические пособия;

- компьютерные обучающие системы в обычном и мультимедийном вариантах; 
- учебно-информационные аудиоматериалы;

- учебно-информационные видеоматериалы и т.п.

Печатные издания, представляющие собой традиционные учебники и учебно-методические пособия, широко используются в системах ДО, где технический уровень оснащения образовательного процесса высок. Как правило, печатные издания для системы дистанционного обучения имеют блочно-модульную структуру, содержат инструкции по изучению материала и организации самостоятельной работы. Обязательными элементами в них являются контрольные задания, толковые словари, вопросы для самопроверки с ответами и тренировочные задания.

В интерактивных базах данных систематизируются массивы данных, которые могут быть доступны посредством телекоммуникаций. Используя эти ресурсы, разработчики курсов, например, могут поддерживать локальные базы данных, как для студентов, так и для преподавателей.

Электронные издания представляют собой электронный вариант печатных учебных материалов, но обладают компактностью хранения в памяти компьютера или на внешнем магнитном носителе, возможностью оперативного внесения изменений и передачи на большие расстояния по электронной почте. При наличии принтера такие издания легко превращаются в твердую копию. Электронные журналы распространяются среди подписчиков через компьютерные сети. Они становятся все более важным источником получения информации и обучения. Студенты подписываются на такие журналы в целях использования их в качестве неотъемлемой части курса или как дополнения к курсовым работам.

Компьютерные обучающие системы (программно-методические комплексы, программные средства учебного назначения, обучающие и контролирующие программы) стали применяться как средства обучения в начале 1970-х годов. В этих средствах отражаются предметные области, в той или иной мере реализуются технологии их изучения, обеспечиваются условия для осуществления различных видов учебной деятельности [11]. Компьютерные обучающие системы позволяют индивидуализировать и дифференцировать процесс обучения, осуществлять контроль с диагностикой ошибок и обратной связью, визуализировать учебную информацию, усиливать мотивацию обучения (например, за счет изобразительных средств программы или использования игровых ситуаций).

Дистанционное обучение предусматривает развитие следующих трех видов технологий:

1 - кейс-технология, когда учебно-методические материалы комплектуются в специальный набор (кейс) и передаются (пересылаются) студенту для самостоятельного изучения с периодическими консультациями и контролем знаний преподавателями;

2 - TB-технология, которая базируется на использовании телевизионных лекций с консультациями; 
ВІСНИК

ОДЕСЬКОГО НАЦІОНАЛЬНОГО

МОРСЬКОГО УНІВЕРСИТЕТУ № 3 (63), 2020
HERALD

OF THE ODESSA NATIONAL

MARITIME UNIVERSITY № 3 (63), 2020

3 - сетевая технология, построенная на использовании возможностей локальных и глобальных сетей как для обеспечения студента учебно-методическим материалом, так и для интерактивного взаимодействия преподавателя и студента.

Видеоконференция в системе дистанционного обучения является одним из самых мощных средств повышения эффективности учебного процесса. Такая телекоммуникационная связь реализует возможность «естественного» общения между преподавателем и студентами виртуальной учебной группы, занимающимися по технологии ДО. Она позволяет не только видеть и слышать друг друга, но и проводить совместное рассмотрение и обсуждение таблиц, графиков, видеосюжетов и т. п.

Высокие темпы технического и технологического прогресса развитых стран требуют как профессионально подготовленных молодых специалистов, так и системного повышения квалификации и профессиональной переподготовки имеющихся кадров для самых различных отраслей. Использование дистанционных образовательных технологий для организации самостоятельной работы студентов создает ряд принципиально новых возможностей (обеспечивает оперативную передачу заданий обучаемым, развивает технические навыки и умения, учит анализировать и синтезировать знания в единое целое, обеспечивает выбор различных источников информации и др.). В образовательных стандартах нового поколения обращается внимание на необходимость формирования у студентов метакомпетенций (общих умений, востребованных в разных предметных областях), особое место отводится проблеме формирования метакомпетенций, связанных с самостоятельной работой и оценочной самостоятельностью. Прежде всего, актуализируется задача развития навыков самостоятельной познавательной и практической деятельности обучающихся, поскольку сегодня основной целью учебного процесса в вузе становится не только усвоение знаний, но и овладение способами этого усвоения, развитие познавательных потребностей и творческого потенциала студентов. Кроме того, достижение высокого уровня личностных результатов обучения, актуализация мотивационных ресурсов обучаемых требует осуществления личностно-ориентированного образовательного процесса, построения индивидуальных образовательных маршрутов и траекторий для каждого обучающегося. В этих условиях широкое использование дистанционных образовательных технологий в вузовском образовании становится требованием времени.

Известное изречение о том, чтобы «наши возможности всегда совпадали с нашими потребностями», действительно верно, ибо такая ситуация гармонизирует любую продуктивную деятельность человека, в том числе и в образовании. Однако в настоящее время наблюдается постоянно растущий разрыв между бурно развивающимися информационно-коммуникационными технологиями (ИКТ) и педагогическими концепциями обучения. Согласно эмпирическому закону, предложенному одним из 
ВІСНИК

ОДЕСЬКОГО НАЦІОНАЛЬНОГО

МОРСЬКОГО УНІВЕРСИТЕТУ № 3 (63), 2020
HERALD

OF THE ODESSA NATIONAL

MARITIME UNIVERSITY № 3 (63), 2020

основателей компании Intel Гордоном Муром, быстродействие микропроцессоров (следовательно, и производительность ИКТ) удваивается каждые полтора года. Появление же новых дидактических принципов и методов обучения пока не может продемонстрировать подобной динамики [5]. Вместе с тем, высокие темпы технического и технологического прогресса развитых стран требуют как профессионально подготовленных молодых специалистов, так и системного повышения квалификации и профессиональной переподготовки имеющихся кадров для самых различных отраслей. Осуществляемая закономерная и логичная смена парадигм: вместо «одно образование на всю жизнь» - «непрерывное образование в течение всей жизни», - делает крайне необходимым внедрение новых, удобных для пользователя индивидуально ориентированных способов получения и использования знаний.

Развитие и широкое распространение информационно-коммуникационных технологий (ИКТ), новых сетевых технологий открыло доступ к мировым информационным ресурсам, породило принципиально новую образовательную среду, создающую все условия для успешной реализации новой парадигмы образования и, более того, для интеграции национальной образовательной системы в глобальную образовательную информационную среду. Среди разнообразной номенклатуры средств ИКТ, которые потенциально могут быть использованы или уже используются в образовании, особо выделим Интернет.

Как отмечает ряд ученых, «под дистанционными образовательными технологиями понимаются образовательные технологии, реализуемые в основном с применением информационных и телекоммуникационных технологий при опосредованном (на расстоянии) или не полностью опосредованном взаимодействии обучающегося и педагогического работника» $[2 ; 6 ; 8]$. Основу образовательного процесса при дистанционном образовании составляет целенаправленная и контролируемая интенсивная самостоятельная работа обучаемого, который может учиться в удобном для себя месте, по индивидуальному расписанию, имея при себе комплект специальных средств обучения и согласованную возможность контакта с преподавателем [3; 7].

Выделим ряд преимуществ дистанционной формы образования:

1. Применение дистанционных технологий для поддержки самостоятельной работы студентов предусматривает не просто выдачу заданий по интернету, но и быструю персональную помощь, подсказку, что позволяет студенту обрести уверенность в правильности принимаемых промежуточных решений.

2. Возрастает интенсивность учебного процесса, появляется возможность доступа к учебным материалам в любое время. Появляется возможность индивидуального on-line диалога с преподавателем вне сетки расписания занятий, что, несомненно, стимулирует образовательный интерес. 
3. Использование ИКТ как прогрессивного средства обучения создает дополнительную мотивацию студентов к познавательной деятельности.

4. Самоконтроль студентами степени освоения материала осуществляется не в конце семестра, а по мере усвоения образовательной программы и т.д. (не успевающий студент может «идти» по индивидуальной образовательной траектории).

Отметим, что определенные трудности вызывает формирование у студентов оценочной самостоятельности, так как в процессе самоанализа молодые люди преодолевают психологический барьер (сопротивление) на пути к осознанию и оценке своих личных качеств, ценностей и социальных ролей. В процессе дистанционного обучения идет накопление опыта рефлексии: у многих студентов происходит актуализация креативности: раскрываются изобразительные, литературные изобретательские творческие способности. Все это создает условия, чтобы студент смог по-новому взглянуть на себя, на свои возможности и перспективы. Такие изменения приводят к кардинальным переменам, в том числе в выборе жизненного пути и даже изменении профессии (обычно через возможности профессиональной переподготовки) в соответствии со своими реальными способностями, интересами и намерениями.

С позиций психолого-педагогических наук высшей школы самостоятельная работа предполагает развитие внутренней мотивации, осознанного отношения к учебной деятельности, формирования рефлексии, целеустремленности, ответственности и главное - интеллектуального удовлетворения от процесса познания и самопознания. Дистанционные формы образования, основанные на принципах развивающего обучения, способствуют эффективной организации самостоятельной работы обучающихся, и в первую очередь - развитию предметной и личной саморегуляции, накоплению опыта рефлексии, навыков эффективного умственного труда, и, как результат, успешной социализации, то есть «вхождению» в профессию и в жизнь [6; 7].

Проблемы, касающиеся развития навыков самообучения у студентов, особенно технических, вузов, на наш взгляд, изучены недостаточно. Такие навыки необходимы студентам уже с первых дней учебы в университете, так как из-за большого потока научной и учебной информации и связанного с этим быстрого устаревания его значение организации самостоятельной работы возрастает.

К необходимым педагогическим условиям сегодня мы относим и дистанционную информационную поддержку, которая, безусловно, влияет на качество образовательной услуги. В этой деятельности ключевым актором становится и библиотека. Начинать работу необходимо с электронного каталога. Студенты смогут быстро найти информацию по любой дисциплине, рационально расходуя свое время и время преподавателя - тьютора. Доступ к электронному каталогу через Интернет позволит 
ВІСНИК

ОДЕСЬКОГО НАЦІОНАЛЬНОГО

МОРСЬКОГО УНІВЕРСИТЕТУ № 3 (63), 2020
HERALD

OF THE ODESSA NATIONAL

MARITIME UNIVERSITY № 3 (63), 2020

обратиться к информации из любой отдаленной точки страны, подключенной к всемирной сети. Отыскав необходимые источники, студентов надо научить работать с информацией критически, уметь выделять главное. Отметим, что особенно важно научить обучающихся способам, приемам и действиям, которые полезны для самостоятельного овладения изучаемым материалом. Эффективная самостоятельная работа - это необходимое условие профессионального роста будущих инженеров.

В процессе дистанционного обучения студент и преподаватель взаимодействуют на расстоянии, эта технология полезна не только для студентов заочной формы обучения. На очном отделении обучается много способной и талантливой молодежи, которая занимается с опережением графика учебного процесса. Они хотят изучать дополнительные дисциплины и формировать профессиональные компетенции, не включенные в данное направление обучения. Поэтому именно дистанционные модули открывают возможности не только для самообразования студентов, но и для преподавателя.

Таким образом, использование дистанционных образовательных технологий для организации самостоятельной работы студентов технического вуза создает ряд принципиально новых возможностей: обеспечивает оперативную передачу заданий обучаемым, интерактивность и оперативную обратную связь, учит пользоваться различными поисковыми системами для получения информации по интересующему вопросу, развивает технические навыки и умения, необходимые пользователям Интернета для коммуникации и сбора информации, обеспечивает доступ и выбор различных источников информации и т.д.

Виртуальная образовательная среда - произвольно конструируемая структура информационной среды, интегрирующаяся совокупностью автономных субъектов, связи которых носят нелинейный, вероятностный характер, и реализующая их жизненные стратегии и ценностные ориентации в интерактивном социальном взаимодействии в условиях институционализации рисков, обусловленных несоответствием реальных и виртуальных образовательных реальностей.

Необходимо подчеркнуть, что согласно мнению єкспертов, в текущем 2019-2020 уч.году за время карантина примерно 60 \% детей воспринимали текущее дистанционное обучение как проблему, влияющую на качество их образования. Примерно четверть не участвовали в онлайнуроках посредством видеоконференций или аудиоконференций со второй половины марта, когда школы закрылись. Около 15 \% учеников не имели дома достаточного технического оборудования для онлайн-обучения, а у $25 \%$ нет соответствующих домашних условий для дистанционных занятий. Также как минимум у половины учителей есть проблемы с онлайнобучением, с одной стороны, с технической точки зрения, но, прежде всего, многие не способны полноценно выполнять онлайн-обучение и активно вовлекать учеников или студентов. 
ВІСНИК

ОДЕСЬКОГО НАЦІОНАЛЬНОГО

МОРСЬКОГО УНІВЕРСИТЕТУ № 3 (63), 2020
HERALD

OF THE ODESSA NATIONAL

MARITIME UNIVERSITY № 3 (63), 2020

Отметим некоторые общие проблемы, возникающих в дистанционном образовании.

1 - характер учебного материала. Эта проблема распространена среди молодых студентов. Учебные материалы должны учитывать значительную долю студентов, которые зачисляются с небольшим опытом или без опыта дистанционного обучения. База учащегося важна при подготовке учебных материалов. Трудно готовить уроки в соответствии с индивидуальными различиями учащихся. Кроме того, предоставляется аналогичный материал для сельских и городских студентов, имеющих разные потребности, опыт и условия обучения.

2 - отсутствие мультимедийной инструкции: больше внимания уделяется отправке материалов. Уроки, написанные для студентов, обычно пишутся учителями, принадлежащими к традиционной системе, и поэтому эти материалы обычно не имеют методики обучения.

3 - отсутствие обратной связи или контакта с преподавателем, поскольку нет ежедневных или еженедельных контактов с учителями с лицом к лицу, у студентов могут возникнуть проблемы с неуверенностью в обучении. Эти неуверенности обнаруживаются в различных вопросах.

4 - отсутствие социального взаимодействия: учащиеся, участвующие в дистанционном образовании, не являются социальными и не могут ответить на различные социальные вопросы и т.д.

Дистанционное обучение может расширить доступ к образованию и подготовке кадров, поскольку его гибкая структура планирования уменьшает эффекты многих временных ограничений и накладываемых обязательств. Кроме того, есть потенциал для расширения коммуникации в сфере образования и доступа к нескольким экспертам в этой и других областях. Современная онлайн-связь позволяет студентам общаться с аккредитованными школами и программами по всему миру, которые очно находятся вне досягаемости для обучения. Это выгодно, потому что студенты имеют возможность «сочетать новые мнения с их собственным, и разработать прочную основу для обучения» $[12 ; 16]$. Для того, чтобы увеличить вероятность того, что студенты будут строить эффективные отношения друг с другом в течение курса, преподаватели должны по возможности использовать аналогичные задания для студентов разных учебных заведений. Высокая стоимость обучения влияет на студентов высших учебных заведений, в которых дистанционное образование может быть альтернативой для того, чтобы обеспечить некоторое облегчение. Дистанционное обучение было более экономически эффективной формой обучения, и иногда может сохранить студенту значительное количество средств, в отличие от традиционного образования. Исследования показали, что высокий уровень удовлетворенности коррелирует с увеличением объёма обучения. Дистанционное обучение может помочь студентам, которые не могут принять участие в традиционной школьной среде, из-за болезни, снижения подвижности и т.п., чтобы получить хорошее 
ВІСНИК

ОДЕСЬКОГО НАЦІОНАЛЬНОГО

МОРСЬКОГО УНІВЕРСИТЕТУ № 3 (63), 2020
HERALD

OF THE ODESSA NATIONAL

MARITIME UNIVERSITY № 3 (63), 2020

образование. Дистанционное образование может обеспечить равный доступ независимо от социально-экономического статуса, места проживания, пола или возраста и т.П. Применение стратегий дистанционного обучения для конкретных студентов по мере надобности может увеличить доступность таких курсов для студентов с различными способностями.

Дистанционное обучение предлагает физическим лицам уникальную возможность воспользоваться опытом и ресурсами лучших университетов в настоящее время. Студенты имеют возможность для совместной работы, обмена, предложить новые методы и технологии для непрерывного совершенствования содержания. Возможность пройти курс в темпе, который подходит для каждого человека и является наиболее эффективным способом, учитывая личные требования по времени и графике. Для самостоятельного дистанционного обучения используются различные в том числе, мобильные устройства, которые обеспечивают максимальную гибкость и широкие возможности.

Существует теоретическая проблема применения традиционных методов обучения на онлайн-курсы, потому что такие курсы могут не иметь верхний предел размера. Д. Барвик [21] отметил, что нет никаких доказательств того, что большой размер класса всегда хуже или что малый размер класса всегда лучше, хотя отрицательная связь была установлена между определенными типами обучения в больших классах $u$ результатов обучения; он утверждал, что высшее образование не сделало достаточные усилия, чтобы экспериментировать с различными методами обучения, чтобы определить, является ли большой размером класса всегда отрищательно коррелируют со снижением результатов обучения. Кроме того, это может быть более трудным для преподавателя организовать и спланировать программу дистанционного обучения, тем более что многие новые программы и их организационные потребности отличаются от традиционной программы обучения.

Более сложная задача дистанционного образования относится к культурным различиям между студентами и преподавателями, а также среди студентов. Программы дистанционного имеют тенденцию быть более разнообразными, так как они могут выходить за рамки географических границ регионов, стран и континентов, а также пересекать культурные границы, которые могут существовать в отношении пола или религии. Это требует правильного понимания и осознания норм, различия, предубеждений и потенциальных проблем, противоречащих друг другу.

Выводы. Выпускник вуза в настоящее время - это высокопрофессиональная личность, способная творчески мыслить, самостоятельно принимать решения и нести за них ответственность. Современный молодой специалист обладает не только набором знаний, умений и навыков, но и сформированной системой компетенций в интеллектуальной, нормативно-правовой, информационной, коммуникативной и других сферах. Кроме того, выпускник должен быть со сформированной гражданской 
идентичностью. Решение этих задач возможно только с усилением роли самостоятельной и научно-исследовательской работы студентов и развитием их творческой активности, чему немало способствуют возможности дистанционного образования. Использование дистанционных технологий, например, в техническом университете направлено не только на подготовку инженера-профессионала, но и на формирование у обучающихся метакомпетенций с помощью личностно-ориентированного образовательного процесса. Методика дистанционного обучения не исчерпывается решением вопросов «чему учить и как учить», но и предполагает разрешение вопроса «как учиться».

Таким образом, дистанционное обучение - это специфичный учебный процесс, который строится, как и любой другой, в соответствии с логикой познавательной деятельности, но реализуется средствами Интернет-технологий, видеоконференций, интерактивного телевидения, другими интерактивными средствами. Основной идеей методики дистанционного обучения является создание учебной информационной среды, включающей в себя компьютерные информационные источники, электронные библиотеки, видео- и аудиотеки, книги и учебные пособия. Информационно-образовательная среда предоставляет уникальные возможности обучаемым для получения знаний как самостоятельно, так и под руководством преподавателей, что представляется весьма перспективным направлением дальнейших исследований.

\section{СПИСОК ЛІТЕРАТУРИ}

1. Ананьев А.Н., Белей А.И. Интернет-технологии как средство информационно-коммуникаиионного обеспечения современного учебного прочесса. 2009. С. 34.

2. Андерсон Т. Три поколения дистанционного образования педагогики. Международный обзор исследований в области открытого и дистанциионного обучения. 2010. № 12 (3). C. 80-97.

3. Андерсон Терри. Теория и практика дистанционного образования. ISBN 978-1897-4250-84.2008. С. 24.

4. Астахова Л.В. Виртуализащия как фактор усиления угроз информачионной безопасности / Л.В. Астахова // Наука ЮУрГУ: материаль 62-й научной конференции. Челябинск, 2010. T. 3. C.5-10.

5. Бредньов А.М., Бредньова В.П. Про системний підхід до використання дистаниійного навчання $у$ вищій школі. Матеріали Х Міжнар. наук.-метод. конф. «Управління якістю підготовки фахівиів». Одеса, 2006. Ч.1. С. 28-30. 
ВІСНИК

ОДЕСЬКОГО НАЦІОНАЛЬНОГО

МОРСЬКОГО УНІВЕРСИТЕТУ

№ 3 (63), 2020
HERALD

OF THE ODESSA NATIONAL

MARITIME UNIVERSITY

6. Бредньов А.М., Бредньова В.П. Про створення контрольних модулів дистанційного навчання при вивченні графічних дисииплін. Матер. ХУІ Міжнар. наук.-метод. конф. «Управління якістю підготовки фахівиів». Одеса, 2011. Ч.1. С.

7. Врредньов А.М., Бредньова В.П. Про поетапне впровадження інноваційних технологій у методологію викладання графічних дисииплін. Матер. XIX-ої Міжнар. наук.метод. конф. "Уnравління якістю підготовки фахівців». Одеса, 2014. Ч. 1. C.158.

8. Бредньова В.П., Бредньов А.М. Про компетентнісний підхід до методології викладання графічних дисииплін для студентівпершокурсників будівельних спеиіальностей. Матер. XXI-ой Міжнар. наук.-метод. конф. «Управління якістю підготовки фахівиів». Одеса, 2016. Ч. 2. С.27-28.

9. Bredneva V., Kosharskaya L., Linetskaya A. Drawing training of students - main basis engineers' education // Bicник ОНМУ. Odеса: Вид-во ОНМУ. 2016. № 3(49). P. 152-157.

10. Bredniova V.P. On the improvement of the methodology of engineer staff's graphic training on the basis of optimization of psychological and pedagogical approaches/Modern Tendencies in Pedagogical Education and Science of Ukraine and Israel: The Way to Integration. Ariel University. 2016, ISSN 2218-8584. Issue № 7. P. 38-42.

11. Бреднёва В.П., Кочарская Л.В. О формировании профессиональных компетенций будущих инженеров в процессе изучения графических дисииплин в вузе. Одеса: Вісник Одеського наиіонального морського університету. 2017, № 2 (51). C. 188-193.

12. Волженина Н.В. Организация самостоятельной работы студентов в процессе дистаниионного обучения: учебное пособие / Н.В. Волюенина. Барнаул: Изд-во Алт. ун-та, 2008. C. 67.

13. Выготский Л.С. Психология развития человека. М.: Изд-во Смысл, 2005. С.1136.

14. Джсонстоун Д.Б. Система высшего образования в США: Структура, руководство, финансирование // Университетское управление: Практика и анализ. 2003. № 5. 92-102 с.

15. Драч I.I. Компетентнісний підхід як засіб модернізації змісту вищої освіти. К.: Інститут інноваційних технологій $i$ змісту освіти МОН України. 2008. Вип.57. С.44-48.

16. Калмыков Д.А. Опыт реаизачии виртуальных образовательных сред / Д.А. Калмыков, Л.А. Хачатуров // Школьные технологии. М., 2002. № 2. 
ВІСНИК

ОДЕСЬКОГО НАЦІОНАЛЬНОГО

МОРСЬКОГО УНІВЕРСИТЕТУ

№ 3 (63), 2020
HERALD

OF THE ODESSA NATIONAL

MARITIME UNIVERSITY

17. Кириллова О.В. Алгоритмитизачия прочесса повыщения профессионального уровня преподавателей в образовательном учреждении / О.В. Кириллова, А.И. Давыдова // Сибирский педагогический журнал. 2010. № 4. С.291-298.

18. Компетентнісний підхід у сучасній освіті: світовий досвід та украӥнські перспективи: Бібліотека з освітньої політики / Під заг. ред. О.В.Овчарук. К., 2004. 112 c.

19. Конюхов М.И, Зыкин С.А. Использование информационных технологий дистанционного обучения при очном обучении. 2016. C.45.

20. Kosharskaya, L. Application of the system approach to the development of the project of a safety management system for navigation in Ukraine / L. Kosharskaya, G. Makhurenko, M. Postan // Technology audit and production reserves. 2017. V. 2. C.23-28.

21. Молнар T.I. Теоретичні основи компетентнісного підходу як освітньої інновачіï. - Zbior artykulow naukowych. ISBN: 978-8365608-78-9. Warszawa, 2017. Stor.21-22.

22. Мур М. Грэм, Уильям Андерсон. Справочник по дистанщионному образованию. Психология Press. ISBN 978-1-4106-0729-4. 2012.- Интернет-издание.

23. Педагогические технологии дистаниионного обучения: учеб. пособие для студ. высш. учеб. Заведений / Е.С. Полат, М.В. Моисеева, А.Е. Петров и др. / Под ред. Е.С. Полат. М.: Издат. иентр «Академия». 2008. С.400.

24. Петерс О. Дистанционное образование и промышленное производство: Сравнительная интерпретация в общих чертах. Отто Петерс по дистанционному образованию: Индустриализация преподавания и обучения. 1994. С.107-127.

25. Рубинштейн С.Л. Основы общей психологии / С.Л. Рубинштейн. СПб.: Издат. «Питер». 2000. С.712.

26. Саба F. Дистанционное образование в США: прошлое, настоящее, будущее. Образовательные технологии. 2011, № 51 (6). C. 11 .

27. Стародубиев В.А. Самоорганизачия в информационной образовательной среде / В.А. Стародубиев // Сибирский педагогический журнал. 2011. № 7. С. 38-47.

28. Терри Эванс, М., Дэвид Мерфи. Международный Справочник по дистаниионному образованию. Бингли: Emerald Group Publishing Limited. 2008. C.221.

29. Журнал «Международный обзор исследований в области открытого и дистанционного обучения», открытый доступ. Интернет-ресурс 
ВІСНИК

ОДЕСЬКОГО НАЦІОНАЛЬНОГО

МОРСЬКОГО УНІВЕРСИТЕТУ
HERALD

OF THE ODESSA NATIONAL

MARITIME UNIVERSITY

30. Bullen, M. 'Distance Education \& Technology Continuing Studies'. 1996.

31. Edge, W., Loegering, J. 'Distance Education: Expanding Learning Opportunities'. 2001

32. Fred Jevons. 'Distance Education and campus - based education: Parity of Esteem'. Eds. Peter Smith and Movis Kelley. Distance Education and the Mainstream. London: Cross Helm. 1987.

33. Goel, A., Goel, S. Distance Education in 21st Century. Deep and Deep Publication, New Delhi. 2009.

34. Keegan, D. Foundations of Distance Education. Routledge Taylor and Francis Group, New York, 1996. P. 10-50.

35. Rogers, C. Freedom to learn for 80 / C. Rogers. - Columbus, OH: Merrill, 1983.

\section{REFERENCES}

1. Ananiev, A., \& Bileyi, A. (2009). Internet-tehnologiyi kak sredstvo informatsionno-komunikatsionnogo obespecheniya sovremennogo uchebnogo protcessa, 34 [in Russian].

2. Anderson, T., \& Dron, J. (2010). Tri pokoleniya distantsionnogo obrazovaniya pedagogiki. Mezhdunarodniyi obzor issledovaniyi $v$ oblasti otkritogo i distantsionnogo obucheniya, 12 (3), 80-97 [in Russian].

3. Anderson, T. (2008). Teoriya $i$ praktika distantsionnogo obrazovaniya. ISBN 978-1897-4250-84, 24 [in Russian].

4. Astahova, L. (2010). Virtualizatsiya kak factor usileniya ugroz informatsionnoyi bezopasnosti// Nauka YUUrGu: Materiali 62 Nauchnoyi Konferentsii. Chast.3, 5-10. - Chelyabinsk [in Russian].

5. Brednyov, A. , \& Brednyova, V. (2006). Pro sistemnyi pidhid do vikoristannia distantsiynogo navchannia u vischiy shkoli. Materiali $X$ Mizhnarodnoi Naukovo-metodychnoi Konferentsii «Upravlinnia yakistiu pidhotovky fakhivtsiv». Chast. 1, 28-30. Odesa: Odeska derzhavna akademiia budivnytstva ta arkhitektury [in Ukrainian].

6. Brednyov, A., \& Brednyova, V. (2011). Pro stvorennia kontrolnih moduliv distantsiynogo navchannia pri vivchenni grafichnyh distsiplin. Mater. XVI Mizhnarodnoi Naukovo-metodychnoi Konferentsii «Upravlinnia yakistiu pidhotovky fakhivtsiv». Chast. 1, 25. Odesa: Odeska derzhavna akademiia budivnytstva ta arkhitektury [in Ukrainian]. 
7. Brednyov, A., \& Brednyova, V. (2014). Pro poetapne vprovadzennya innovatsiynih tehnologiy u metodologiyu vikladannya grafichnyh distsiplin. Mater. XIX Mizhnarodnoi Naukovo-metodychnoi Konferentsii "Upravlinnia yakistiu pidhotovky fakhivtsiv». Chast. 1, 158. Odesa: Odeska derzhavna akademiia budivnytstva ta arkhitektury [in Ukrainian].

8. Brednyova, V., \& Brednyov, A. (2016). Pro kompetentnisnyi pidkhid do metodologii vykladannia grafichnyh distsiplin dlya studentiv-pershokursnykiv budivelnyh spetsialnostei. Mater. XXI Mizhnarodnoi Naukovo-metodychnoi Konferentsii «Upravlinnia yakistiu pidhotovky fakhivtsiv». Chast. 2, 27-28. Odesa: Odeska derzhavna akademiia budivnytstva ta arkhitektury [in Ukrainian].

9. Brednyova, V.P., Kosharskaia, L.V., Linetskaya A. (2016). Drawing training of students - main basis engineers' education. Visnik Odeskogo Natsionalnogo Morskogo Universitetu, 3(49), 152-157. Odesa: [in English].

10. Bredniova, $V$. (2016). On the improvement of the methodology of engineer staff's graphic training on the basis of optimization of psychological and pedagogical approaches / Modern Tendencies in Pedagogical Education and Science of Ukraine and Israel:The Way to Integration. Ariel Un-ty. Issue.7, 38-42. ISSN 2218-8584. Odesa: [in English].

11. Brednyova, V., \& Kosharskaia, L. (2017). O formirovanii professionalnyh kompetentsii budushchikh inzhenerov $v$ protsesse izucheniia graficheskih distsiplin $v$ vuze. Visnik Odeskogo Natsionalnogo Morskogo Universitetu, 2 (51), 188-193. Odesa: [in Russian].

12. Volzhenina, N. (2008). Organizatsiya samostoyatelnoyi raboti studentov $v$ protsesse distantsionnogo obucheniya: uchebnoye posobiye / N.Volzhenina. Barnaul: Izd-vo Alt. Un-ta, 67 [in Russian].

13. Vigotskiy, L. (2005). Psihologiya razvitiya cheloveka. Moskva: Izd-vo Smisl, 1136 [in Russian].

14. Dzhonstoun, D. (2003). Sistema visshego obrazovaniya v SSHA: Struktura, rukovodstvo, finansirovaniye // Universitetskoe upravleniye: Praktika I analiz, 5, 92-102 [in Russian].

15. Drach, I. (2008). Kompetentnisnyi pidkhid yak zasib modernszatsii zmistu vishchoi osviti. Institut inovatsiynih tehnologiy. Kyiv: Vip.57, 44-48 [in Ukrainian].

16. Kalmikov, D. (2002). Opit realizatsii virtualnih obrazovatelnih sred / D. Kalmikov, L. Hachaturov// Shkolniye tehnologii. Moskva, 2 [in Russian]. 
17. Kirilova, O. (2010). Algoritmitizatsiya protsessa povisheniya professionalnogo urovnya prepodavateleyi $v$ obrazovatelnom uchrezhdenii / O. Kirilova, A. Davidova // Sibirskiyi pedagogicheskiyi zhurnal, 4, 291-298 [in Russian].

18. Kompetentnisnyi pidkhid u suchasnii osviti: svitovyi dosvid ta ukrainski perspektivi / Pid zag.red Ovcharuk, O. V. (2004). Kyiv: Biblioteka z osvitnoi polityky, 121 [in Ukrainian].

19. Konyuhov, M., Zikin C. (2016). Ispolzovaniye informatsionnih tehnologiyi distantsionnogo obucheniya pri ochnom obuchenii, 45 [in Russian].

20. Kosharskaya, L. (2017). Application of the system approach to the development of the project of a safety management system for navigation in Ukraine / L. Kosharskaya, G. Makhurenko, M. Postan // Technology audit and production reserves, 2, 23-28 [in English].

21. Molnar, T. I. (2017). Teoretychni osnovy kompetentnisnoho pidkhodu yak osvitnoi innovatsii [Theoretical foundations of competence approach as educational innovation]. Zbior artykulow naukowych (ISBN:978-83-65608-78-9). Warszawa: 21-22 [in Ukrainian].

22. Mur, M., Uilyam, A. (2012). Spravochnikpo distantsonnomu obrazovaniyu. Psihologiya Press. ISBN 978-1-4106-0729-4. Internet- izdaniye [in Russian].

23. Pedagogicheskiye tehnologii distantsionnogo obucheniya: uchebnoye posobiye dlya stud. Visshih ucheb. zaved. (2008)/E. Polat, M. Moiseeva. A. Petrov \& drug. Moskva: Izdat. Tsentr Akademiya, 400 [in Russian].

24. Peters, O. (1994). Distantsionnoye obrazovaniye i promishlennoye proizvodstvo; Sravnitelnaya interpretatsiya $v$ obshchih chertah: Industrializatsiya prepodavaniya I obucheniya, 107-127 [in Russian].

25. Rubinshtein, S. (2000). Osnovi obshcheyi psihologii / S. Rubinshtein: S.-Peterb.: Izd-vo Piter, 712 [in Russian].

26. Saba, F. (2011). Distantsionnoye obrazovaniye v SSHA: proshloye, nastoyashcheye, budushcheye. Obrazovatelniye tehnologii, 51(6), 11 [in Russian].

27. Starodubtsev, V. (2011). Samoorganizatsiya $v$ informatsionnoyi obrazovatelnoyi srede / $V$. Starodubtsev // Sibirskiyi pedagogicheskiyi zhurnal, 7, 38-47 [in Russian].

28. Stepanenko, S. (2007). Pro transformatsiyu sistemi zaochnoi osviti $v$ umovah integratsii $v$ Evropeyskiyi osvitniyi prostir. Vishcha shkola, 2, 31-37 [in Ukrainian]. 
ВІСНИК

ОДЕСЬКОГО НАЦІОНАЛЬНОГО

МОРСЬКОГО УНІВЕРСИТЕТУ

№ 3 (63), 2020
HERALD

OF THE ODESSA NATIONAL

MARITIME UNIVERSITY

№ 3 (63), 2020

29. Evans, T., Merfi, D. (2008). Mezhdunarodniyi Spravochnik po distantsionnomu obrazovaniyu. Bingli: Emerald Group Publishing Limited, 221 [in Russian].

30. Hasson, V. (2004). Kriterii yakosti distantsiyinoi osviti. Vishcha osvita, 1, 92-99 [in Ukrainian].

31. Problemi vprovadzhennya distantsiyinoi osviti v Ukraini. http: // edu. minfin.gov.ua/ Learning Process/ Remote Education / Pages [in Ukrainian].

32. Edge, W., Loegering, J. (2001). Distance Education: Expanding Learning Opportunities [in English].

33. Jevons, F. (1987). Distance Education and campus - based education: Parity of Esteem. Distance Education and the Mainstream. London [in English].

34. Kosharskaia, L., Brednyova, V., Levitskyi A. (2020). Sovremennoye sostoyaniye morskogo obrazovaniya. Mezhdunarodniyi opit. Monografiya. V.1, 114. Odessa, Odeskiyi Natsionalniyi Morskoyi Universitet [in Russian].

Стаття надійшла до редакиії 18.03.2020

Посилання на статтю: Кошарская Л.В., Бреднёва В.П., Левицкий А.В. Исследования проблемы формирования современных подходов к методологии дистанционного обучения // Вісник Одеського національного морського університету: Зб. наук. праць, 2020. № 3(63). C. 165-186. DOI 10.47049/22261893-2020-3-165-186.

Article received 18.03.2020

Reference a JournalArtic: Kosharska L., Brednyova V., Levytsckiy A. Researches of problem of forming of modern going near methodology of the controlled from distance educating // Herald of the Odessa national maritime university. 2020. 3(63), 165-186. DOI 10.47049/2226-1893-2020-3-165-186. 